\title{
Control of the nanoscale crystallinity and phase separation in polymer solar cells
}

\author{
Chih-Wei Chu, ${ }^{1, a)}$ Hoichang Yang, ${ }^{3}$ Wei-Jen Hou, ${ }^{1}$ Jinsong Huang, ${ }^{1}$ Gang Li, ${ }^{1,2, b)}$ and \\ Yang Yang ${ }^{1, c)}$ \\ ${ }^{1}$ Department of Materials Science and Engineering, University of California, Los Angeles, \\ California 90095, USA \\ ${ }^{2}$ Solarmer Energy, Inc. El Monte, California 91731, USA \\ ${ }^{3}$ Rensselaer Nanotechnology Center, Rensselaer Polytechnic Institute, Troy, New York 12180, USA
}

(Received 8 January 2008; accepted 31 January 2008; published online 11 March 2008)

\begin{abstract}
Grazing-incidence $\mathrm{x}$-ray diffraction and atomic force microscopy were performed on bulk heterojunction regioregular poly(3-hexylthiophene) (RR-P3HT) [6,6]-phenyl-C 71 -butyric acid methyl esters spin-cast films with different film processing conditions to correlate the crystalline nanostructure of P3HT with the corresponding solar cell performance. The increase in long wavelength absorption for solvent annealed films is related to highly conjugated crystal structure of RR-P3HT phase-separated in the active layer. Upon thermal annealing, the solvent annealed 50-nm-thick device shows high solar cell performance with fill factor up to $73 \%$ and power conversion efficiency of 3.80\%. (C) 2008 American Institute of Physics. [DOI: 10.1063/1.2891884]
\end{abstract}

Bulk heterojunction $(\mathrm{BHJ})$ solar cells ${ }^{1}$ based on regioregular poly(3-hexylthiopene) (RR-P3HT) and fullerene have achieved $4-5 \%$ power conversion efficiency (PCE) ${ }^{2-10}$ The incident photon conversion efficiency (IPCE) is approaching that of that of their inorganic semiconductor counterparts. $^{3,4,6,8}$ The major limitation is the absorption of the polymers in the solar spectrum. Further progress in materials as well as device architecture ${ }^{9}$ is required.

In this manuscript, grazing-incidence $\mathrm{X}$-ray diffraction (GIXRD) highlights that controlled film processing can tune polymer nanostructure in RR-P3HT/ fullerene blend films. High efficiency device was achieved with an optically thin layer ( $\sim 50 \mathrm{~nm}$ thickness). It is possible to further improve polymer solar cells efficiency via multiple device stacking or tandem structure. ${ }^{11,12}$

For GIXRD, RR-P3HT (Rieke Metals, Inc)/[6,6]phenyl-C71-butyric acid methyl esters $([70] \text { PCBM })^{13}$ (Solenne B. V.) (1:1 in weight) films were spin cast (room temperature) on poly(3,4-ethylenedioxythiophened): poly(styrene sulfonate) (PEDOT:PSS)-coated glass substrates, from solutions with $20 \mathrm{mg} / \mathrm{ml}$ of both components in either 1,2 dichlorobenzene (DCB) (boiling point, $T_{b}$ $\left.=180{ }^{\circ} \mathrm{C}\right) \quad$ or $\quad$ chlorobenzene $(\mathrm{CB}) \quad\left(T_{b}=131^{\circ} \mathrm{C}\right)$. Synchrotron-based GIXRD procedure is described elsewhere. $^{14}$

Figure 1(a) shows 2D GIXRD patterns of P3HT/ [70]PCBM films from solutions in DCB (for 1 and 2) and $\mathrm{CB}$ (for 3 and 4). For the sample 2, DCB is completely evaporated during spin casting at $1000 \mathrm{rpm}$ for $90 \mathrm{~s}$, while a relatively short time of $30 \mathrm{~s}$ provides solvent-annealing effect on the sample 1 still containing small amounts of the solvent residue. The film thickness is $\sim 150-160 \mathrm{~nm}$. In the 2D GIXRD patterns of the two samples, intense reflections

\footnotetext{
${ }^{a}$ Present address: Research Center for Applied Sciences, Academia Sinica, Nankang, Taipei, Taiwan 11529.

b) Author to whom correspondence should be addressed. Electronic mail: gang1@solarmer.com.

${ }^{c)}$ Author to whom correspondence should be addressed. Electronic mail: yangy@ucla.edu.
}

of (h00) and (010) crystal planes of RR-P3HT are indicated along the $q_{z}$ and $q_{x y}$ axis, respectively, corresponding to $\pi$-conjugated planes in RR-P3HT crystals, where hexyl side chains of RR-P3HT have an edge-on structure with respect to the substrate. In contrast, fast solvent evaporation conditions by relatively volatile $\mathrm{CB}$ induce less-ordered crystalline structure of RR-P3HT in the sample 3 (1000 rpm, $90 \mathrm{~s}$ ) and 4 (3000 rpm, $90 \mathrm{~s}$ ), as confirmed in AFM topography showing less crystalline RR-P3HT [Fig. 1(d)]. In addition, samples 3 and 4 contain high portion of kinetically favorable face-on structure of RR-P3HT crystals (i.e., the side chain parallel to the substrate), as confirmed by intense reflection of (010) crystal planes (with a layer spacing of $3.81 \AA$ ) along the $q_{x y}$ axis in the 2D GIXRD patterns. ${ }^{14,15}$ From onedimensional (1D) out-of-plane X-profiles for the P3HT/ [70]PCBM films examined [Fig. 1(b)], we found that sample 1 with the longest crystal growth time has the highest crystallinity, although the edge-on molecular ordering becomes broader by crystal growth of RR-P3HT in a pseudosolidlike state [Fig. 1(c)]. An increase in polymer interlayer spacing is clearly observed-16.3 $\AA$ in $1,16.5 \AA$ in $2,16.8 \AA$ in 3 , and $16.9 \AA$ in 4 . As a result, the controlled evaporation rate of high boiling solvent is one strategy to induce highly ordered and crystalline RR-P3HT in the blend film. This provides freedom to make high efficient solar cells with wide various film thickness.

The polymer solar cells in this study were constructed on indium tin oxide (ITO) coated glass substrates modified by PEDOT:PSS. In order to systematically control solvent evaporation rate, RR-P3HT/[70]PCBM (20:20 mg/ml) was dissolved in 1,2,4-trichlorobenzene (TCB) with a high $T_{b}$ of $214.4^{\circ} \mathrm{C}$. The active layer was deposited by spin casting at $3000 \mathrm{rpm}$ ( $\sim 50 \mathrm{~nm}$, measured by Dektek profilometer). The slow growth process is carried out by covering active layer in a petri dish immediately after spin casting for $50 \mathrm{~s}$. By spin casting at $3000 \mathrm{rpm}$ for $180 \mathrm{~s}$, the film was completely dry and hereby still referred as "fast growth." Thermal annealing is at $110^{\circ} \mathrm{C}$ for $15 \mathrm{~min}$. The absorption measurement was performed using Varian Cary $50 \mathrm{UV}$-visible spectrophotometer. $25 \mathrm{~nm}$ of $\mathrm{Ca}$ and $100 \mathrm{~nm}$ of $\mathrm{Al}$ were thermally evapo- 

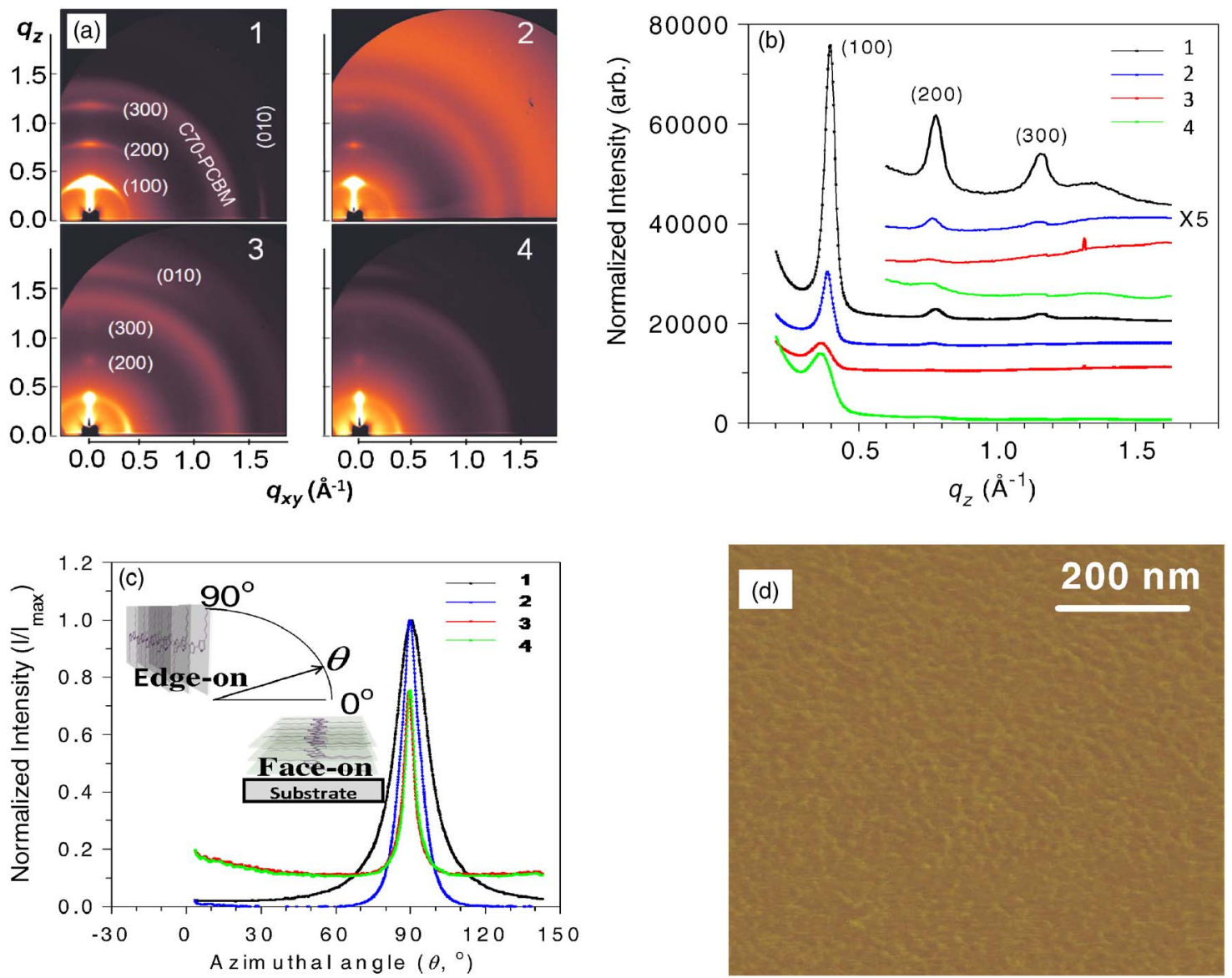

FIG. 1. (Color online) (a) 2D GIXRD patterns of four RR P3HT/[C70]PCBM (1:1 ratio) films [(1) DCB, $1000 \mathrm{rpm} 30 \mathrm{~s}$; (2) DCB, $1000 \mathrm{rpm} 90 \mathrm{~s}$; (3) CB, $1000 \mathrm{rpm} 90 \mathrm{~s}$; (4) CB, $3000 \mathrm{rpm}, 90 \mathrm{~s}$. (b) $1 \mathrm{D}$ out-of-plane x-ray profiles. (c) Azimuthal scan profiles obtained at $q(100)$ peak positions. The inset in (c) represents the correlation between the measured azimuthal angle and molecular orientation of RR P3HT. (d) Tapping mode AFM phase image of film 4.

rated through a shadow mask under a vacuum of $10^{-6}$ Torr. Testing procedures follow Ref. 4.

Figure 2 shows the effect of growth process on the absorbance for the thin films of RR-P3HT:[70]PCBM $(1: 1 \mathrm{wt} \%)$, before and after thermal annealing at $110{ }^{\circ} \mathrm{C}$. Although the fast-grown film is more homogeneous and smooth, the spectral features of P3HT subsides dramatically, which is attributed to [70]PCBM induced destruction of the RR-P3HT chain packing (ordering). ${ }^{16}$ On the other hand, the absorption spectra of solvent annealed film has very pronounced vibronic peaks, indicating strong interchain interaction among RR-P3HT chains as well as phase segregation. Thermal annealing significantly enhances the absorption of fast-grown film in long-wavelength region, although cannot match that in solvent annealed films. This indicates that the latter is more efficient in enhancing RR-P3HT chain packing and crystallinity. The IPCE data follow the same trend [Fig 2(b)]. The IPCE of the slow-growth device with thermal annealing is $54 \%$ and the plateau is also broader in the red region. This agrees with the improved light harvesting and carrier mobility of RR-P3HT.

The illuminated $\left(100 \mathrm{~mW} / \mathrm{cm}^{2}\right) J-V$ characteristics are shown in Fig. 3(a). The fast-growth film without thermal treatment shows $J_{\mathrm{SC}}=3.21 \mathrm{~mA} / \mathrm{cm}^{2}, V_{\mathrm{OC}}=0.72 \mathrm{~V}$, and fill factor $(\mathrm{FF})=29.81 \%$, which translates to a PCE of $0.69 \%$. Slow-growth process dramatic improvement is observed in both $J_{\mathrm{SC}}$ and FF, which results in PCE $=3.32 \%$. Both enhanced absorption and carrier mobility enhancement due to the significant polymer ordering in the film are believed to responsible to the improvements. The best device performance is achieved with slow-growth film combined with thermal annealing at $110{ }^{\circ} \mathrm{C}\left(J_{\mathrm{SC}}=8.59 \mathrm{~mA} / \mathrm{cm}^{2}, \quad V_{\mathrm{OC}}\right.$ $=0.62 \mathrm{~V}, \mathrm{FF}=71.3 \%$, and $\mathrm{PCE}=3.80 \%$ ). Thermally annealed fast-grown device gets major boost in $J_{\mathrm{SC}}$ (from 3.21 to $7.56 \mathrm{~mA} / \mathrm{cm}^{2}$ ) and FF (from $29.8 \%$ to $53.3 \%$ ). As expected, the resulting $2.49 \%$ PCE is significantly lower than that of purely solvent annealed device.

The $V_{\mathrm{OC}}, J_{\mathrm{SC}}$, and FF of the device with both solvent and thermal annealing as function of the incident light intensity $\left(P_{\text {in }}\right)$ are plotted in Fig. 3(b). FF reaches a maximum of $73.1 \%$ at an incident intensity of $20 \mathrm{~mW} / \mathrm{cm}^{2}$. The FF remains at $71.3 \%$ at $\mathrm{AM} 1.5 \mathrm{G} 100 \mathrm{~mW} / \mathrm{cm}^{2}$ illumination. These values are among the highest reported numbers in organic solar cells so far. The improved FF provides hint of improved transport property, which could be attributed to the fact that the charge became easier to extract due to the lower thickness of active layer. Table I summarizes the solar cell

TABLE I. Summary of device performance of ITO/PEDOT:PSS/ P3HT:PCBM (film thickness $\sim 50 \mathrm{~nm}$ )/Ca/Al polymer solar cells with different fabrication conditions.

\begin{tabular}{lcccrc}
\hline \hline \multicolumn{1}{c}{ Condition } & $\begin{array}{c}V_{\mathrm{oc}} \\
(\mathrm{V})\end{array}$ & $\begin{array}{c}J_{\mathrm{sc}} \\
\left(\mathrm{mA} / \mathrm{cm}^{2}\right)\end{array}$ & $\begin{array}{c}\mathrm{FF} \\
(\%)\end{array}$ & $\begin{array}{c}R_{S} \\
\left(\Omega / \mathrm{cm}^{2}\right)\end{array}$ & $\begin{array}{r}\text { PCE } \\
(\%)\end{array}$ \\
\hline Fast grown, annealed & 0.62 & 7.56 & 53.27 & 5.1 & 2.49 \\
Fast grown, as-cast & 0.72 & 3.21 & 29.81 & 10.1 & 0.69 \\
Slow grown, annealed & 0.62 & 8.59 & 71.3 & 1.7 & 3.80 \\
Slow grown, as-cast & 0.61 & 8.33 & 66.39 & 4.4 & 3.32 \\
\hline \hline
\end{tabular}



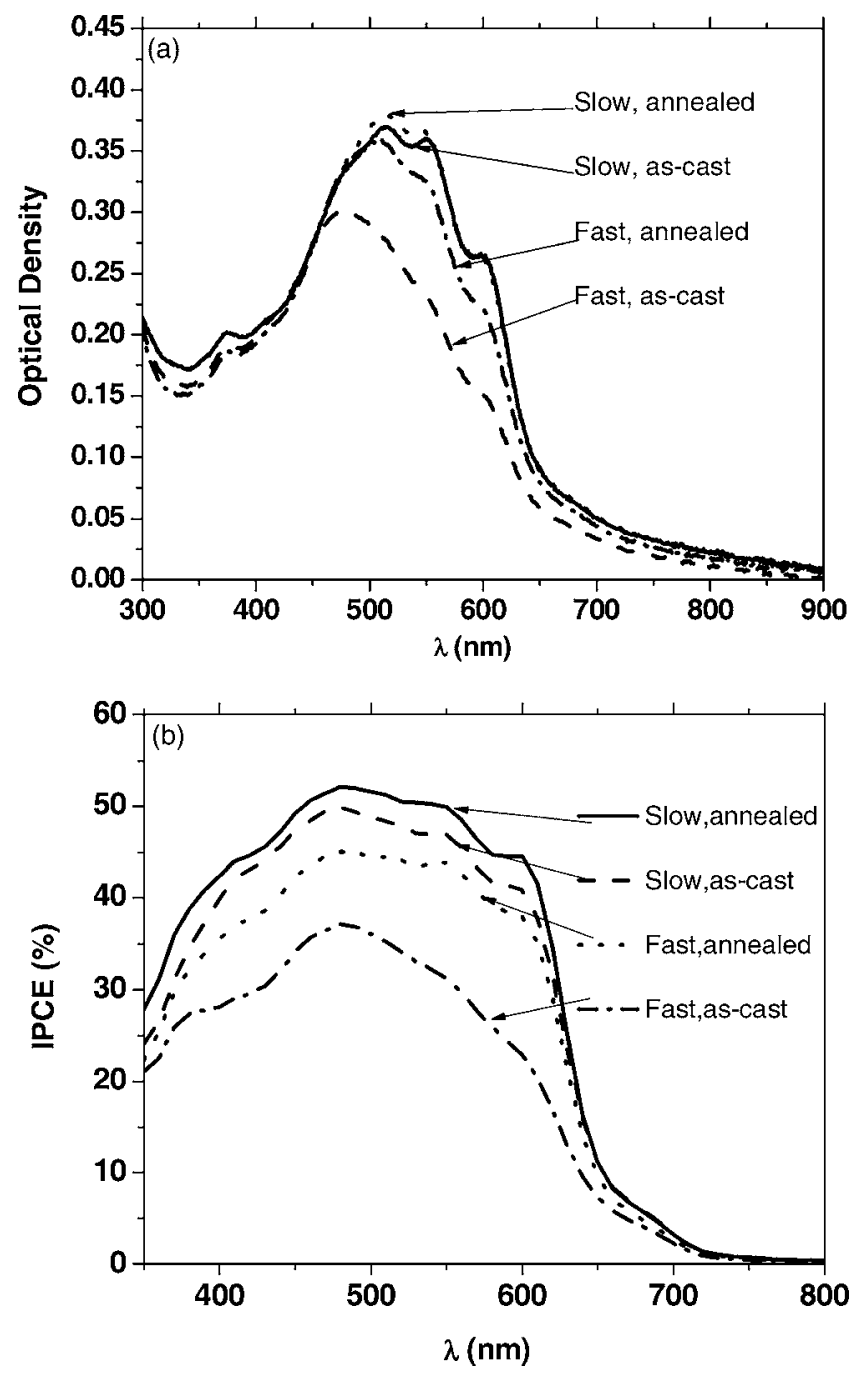

FIG. 2. (a) UV-visible spectra for films of P3HT:[70]PCBM (in 1:1 wt/wt ratio), for both slow grown and fast grown films from TCB as solvent, before (dash line) and after (solid line) annealing. The films were spun cast at $3000 \mathrm{rpm}$ for $50 \mathrm{~s}$ (film thickness $\sim 50 \mathrm{~nm}$ ) and the annealing was done at $110{ }^{\circ} \mathrm{C}$ for $15 \mathrm{~min}$ inside glove box. (b) IPCE of RR-P3HT:[70]PCBM solar cells with two types of active layers: fast grown and slow grown.

performance of all devices discussed in this study.

The performance improvement through solvent annealing can be explained by film morphology. While RR-P3HT self-organizes to fibrillar highly crystalline domains with perdiodicity close to twice the exciton diffusion length, ${ }^{16}$ it leads to a percolated network of both crystalline RR-P3HT and [70]PCBM, i.e., a quasi-optimized morphology for polymer solar cell. PCBM is believed to play a minor role because solvent annealing is at room temperature.

In conclusion, we have shown that film processing conditions can control polymer nanoscale crystallinity and phase separation using GIXRD and AFM techniques. Efficient polymer solar cells $(3.80 \%$ under AM $1.5 \mathrm{G}$ illumination at $100 \mathrm{~mW} / \mathrm{cm}^{2}$ ) based on thin P3HT:[70]PCBM heterojunction with low optical density have been demonstrated. The enhancement of the $J_{\mathrm{SC}}$ and FF of the solvent annealed device with thermal treatment compared to the fast-growth device without thermal treatment is attributed to increase absorption in red region and improved charge transfer properties.
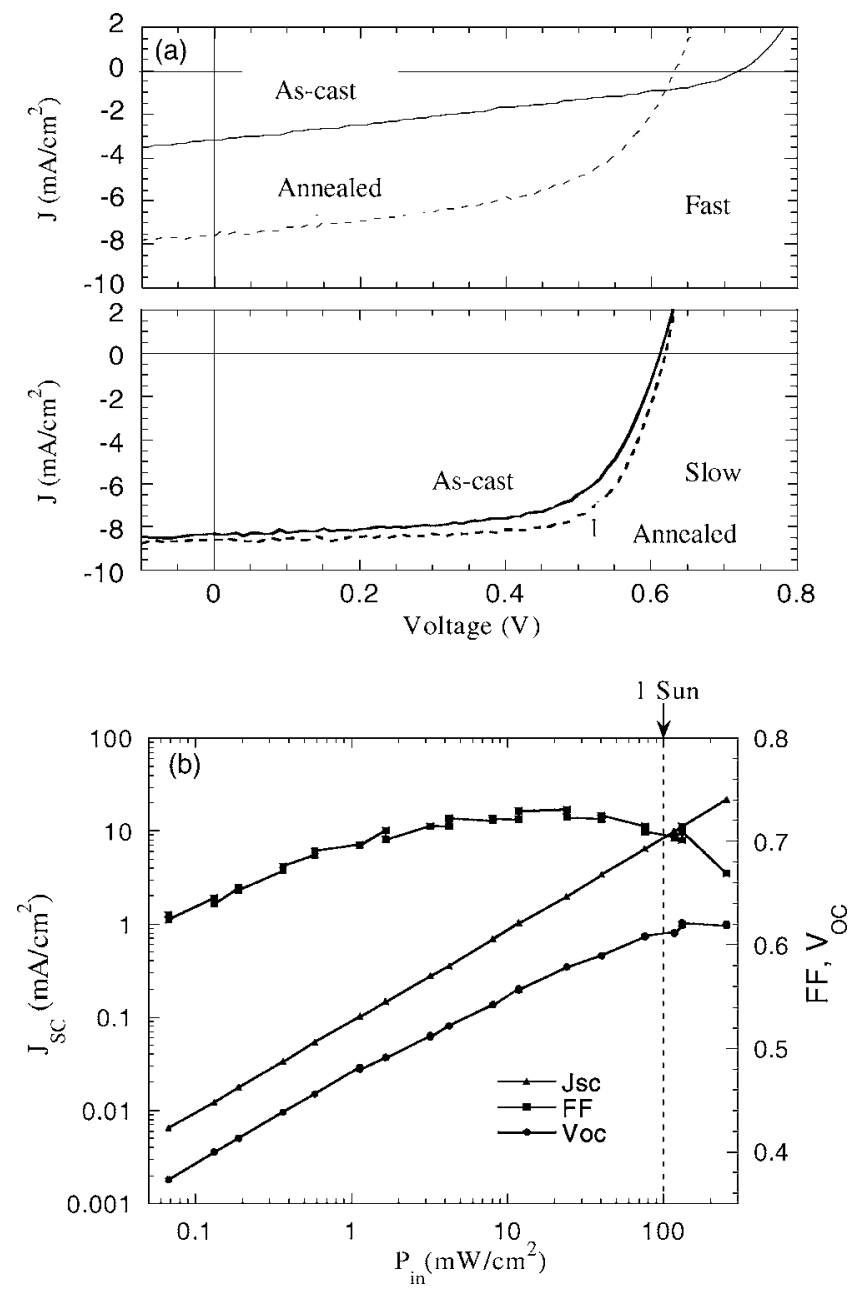

FIG. 3. (a) $J-V$ characteristics of the fast (top) and slow (bottom) grown devices under AM $1.5 \mathrm{G}$ illumination with intensity of $100 \mathrm{~mW} / \mathrm{cm}^{2}$. (b) $J_{\mathrm{SC}}$ (triangles), FF (squares), and $V_{\mathrm{OC}}$ (circles), as a function of the incident power density $\left(P_{\text {in }}\right)$ for the slow grown devices with annealing at $110{ }^{\circ} \mathrm{C}$.

${ }^{1}$ G. Yu, J. Gao, J. C. Hummelen, F. Wudl, and A. J. Heeger, Science 270, 1789 (1995).

${ }^{2}$ Y. Kim, S. A. Choulis, J. Nelson, D. D. C. Bradley, S. Cook, and J. R. Durrant, Appl. Phys. Lett. 86, 063502 (2005).

${ }^{3}$ F. Padinger, R. S. Rittberger, and NS. Sariciftci, Adv. Funct. Mater. 13, 85 (2003).

${ }^{4}$ G. Li, V. Shrotriya, J. Huang, Y. Yao, T. Moriarty, K. Emery, and Y. Yang, Nat. Mater. 4, 864 (2005).

${ }^{5}$ G. Li, V. Shrotriya, Y. Yao, and Y. Yang, J. Appl. Phys. 98, 043704 (2005).

${ }^{6}$ W. Ma, C. Yang, X. Gong, K. Lee, and A. J. Heeger, Adv. Funct. Mater. 15, 1617 (2005).

${ }^{7}$ M. Nakazono, T. Kawai, and K. Yoshino, Chem. Mater. 6, 864 (1994).

${ }^{8}$ P. Schilinsky, C. Waldauf, and C. J. Brabec, Appl. Phys. Lett. 81, 3885 (2002).

${ }^{9}$ G. Li, C.-W. Chu, V. Shrotriyz, J. Haung, and Y. Yang, Appl. Phys. Lett. 88, 253503 (2006).

${ }^{10}$ J. Huang, G. Li, and Y. Yang, Appl. Phys. Lett. 87, 112105 (2005).

${ }^{11}$ V. Shrotriya, E. H. Wu, G. Li, Y. Yao, and Y. Yang, Appl. Phys. Lett. 88, 064104 (2006).

${ }^{12}$ K. Kawano, N. Ito, T. Nishimori, and J. Sakai, Appl. Phys. Lett. 88, 073514 (2006)

${ }^{13}$ M. M. Wienk, J. M. Kroon, W. J. H. Verhees, J. Knol, J. C. Hummelen, P. A. van Hal, and R. A. J. Janssen, Angew. Chem. 42, 3371 (2003).

${ }^{14}$ H. Yang, S. W. LeFevre, C. Y. Ryu, and Z. Bao, Appl. Phys. Lett. 90, 172116 (2007).

${ }^{15}$ V. Shrotriya, G. Li, Y. Yao, Y. Yang, T. Moriarty, and K. Emery, Adv. Funct. Mater. 16, 2016 (2006).

${ }^{16} \mathrm{G}$. Li, Y. Yao, H. Yang, V. Shrotriya, G. Yang, and Y. Yang, Adv. Funct. Mater. 17, 1636 (2007). 